\title{
Accumulate evidence for IP-10 in diagnosing pulmonary tuberculosis
}

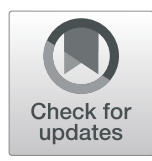

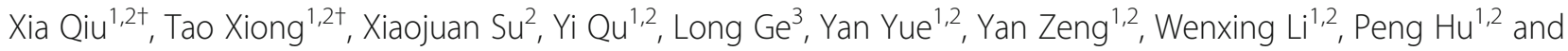
Dezhi Mu ${ }^{1,2^{*}}$

\begin{abstract}
Backgrounds: Pulmonary tuberculosis (PTB) is a major health and economic burden. Accurate PTB detection is an important step to eliminating TB globally. Interferon gamma-induced protein 10 (IP-10) has been reported as a potential diagnostic marker for PTB since 2007. In this study, a meta-analysis approach was used to assess diagnostic value of IP-10 for PTB.

Methods: Web of Science, PubMed, the Cochrane Library, and Embase databases were searched for studies published in English up to February 2019. The pooled sensitivity, specificity, positive likelihood ratio (PLR), negative likelihood ratio (NLR), diagnostic odds ratio (DOR), the area under the curve (AUC) and hierarchical summary receiver operating characteristic (HSROC) curve were estimated by the HSROC model and random effect model.

Results: Eighteen studies including 2836 total participants met our inclusion criteria. The pooled sensitivity, specificity, PLR, and NLR of IP-10 for PTB detection were 86,88\%, 7.00, and 0.16, respectively. The pooled DOR was 43.01, indicating a very powerful discriminatory ability of IP-10. The AUC was 0.93 ( $95 \% \mathrm{Cl}$ : $0.91-0.95$ ), showed the accuracy of IP-10 was good. Meta-regression showed that there was no heterogeneity with respect to TB burden, study design type, age, IP-10 assay method, IP-10 condition and HIV-infection status.
\end{abstract}

Conclusions: Our results showed that IP-10 is a promising marker for differentiating PTB from non-TB.

Keywords: Pulmonary tuberculosis, Interferon gamma-induced protein 10, Diagnosis, Meta-analysis

\section{Background}

Tuberculosis (TB), a highly contagious disease, is still a major health and economic burden [1]. Globally, approximately 10 million individuals developed $\mathrm{TB}$ and more than 1.3 million died of the disease in 2017, according to a WHO report [2]. Pulmonary tuberculosis (PTB), accounting for $75 \%$ of all $\mathrm{TB}$ cases, contributes substantially to $\mathrm{TB}$ mortality, especially with HIV co-infection [3, 4]. Correctly discriminating PTB is an important step to eliminate TB by 2030, a goal established by the WHO [2].

In clinical practice, sputum smear microscopy is ineffective for detecting PTB [5]. Specimen culture for $M t b$ provides the most accurate diagnosis [6]. However, the

\footnotetext{
* Correspondence: mudz@scu.edu.cn

${ }^{+}$Xia Qiu and Tao Xiong contributed equally to this work.

'Department of Pediatrics, West China Second University Hospital, Sichuan University, Chengdu 610041, Sichuan, China

${ }^{2}$ Key Laboratory of Obstetric \& Gynecologic and Pediatric Diseases and Birth

Defects of Ministry of Education, Sichuan University, Chengdu, China
}

Full list of author information is available at the end of the article results of microbiological examination and acid-fast bacillus stains depend on the sputum sample. Immunological tests, such as the tuberculin skin test (TST) and interferon-gamma release assay (IGRA), are auxiliary diagnostic tools for PTB [7]. TST has a low specificity in Bacilli Calmette Guerin (BCG)-vaccinated individuals [7]. In children, IGRAs can yield many indeterminate results $[8,9]$. Considering these limitations, additional valid tools are required to improve the diagnosis of PTB.

Interferon gamma-induced protein 10 (IP-10), an IFNgamma-inducible chemokine, could be expressed at 100fold higher levels than those of IFN-gamma after TB infection $[10,11]$. Age and gender do not affect the level of IP-10 [11, 12]. Since 2007, IP-10 has been reported as a potential parameter for PTB detection [7, 13-29].

Many studies have evaluated the diagnostic potential of IP-10 for PTB, but the results are variable. Therefore, the aim of this study was to synthesize and analyze the diagnostic value of IP-10 for PTB. 


\section{Methods}

\section{Literature search}

This study followed the Preferred Reporting Items for Systematic Reviews and Meta-Analyses Diagnostic Test Accuracy criteria 2018 (PRISMA-DTA 2018) [30]. The Web of Science, PubMed, the Cochrane Library and Embase databases were used to search for relevant English language citations published up to February 2019. Our search terms were "tuberculosis," "pulmonary tuberculosis," "Chemokine CXCL10," and "interferon gammainduced protein 10." Comprehensive literature search strategies were used based on the following combination of MeSH terms, title/abstracts and all fields for these databases (Additional file 1: Table S1). Additionally, the reference lists of the applicable studies, relevant research letters, and reviews were manually searched to find other potentially relevant studies.

\section{Literature selection}

Two investigators independently determined literature eligibility. Studies reporting IP-10 levels for the detection of PTB were included according to the following criteria: (1) reporting on individuals with PTB and non-TB (population); (2) provision of IP-10 in whole blood and plasma as index test; (4) $M t b$ culture as a gold standard, and other reference standard including pathological examination, microscopy and genexpert MTB/RIF test (WHO recommended) [2]; (5) the primary outcomes including diagnostic performance of IP-10 (sensitivity and specificity); (5) randomized controlled trails, prospective and retrospective studies included (study design); (6) more than 10 individuals reported meeting the inclusion criteria. Studies not published in English, other letters (except research letters), conference abstracts, veterinary experiments, reviews and case reports were excluded.

\section{Data extraction}

The following data were extracted: the first author, year of publication, country, TB high-burden, study design, age, number of participants (patients with PTB and nonTB subjects), TB site, non-TB status, cut-off for index test (IP-10), diagnostic reference standard, method and condition for the IP-10 assay, HIV-infection status, sensitivity, specificity, true positive (TP), false positive (FP), false negative (FN), and true negative (TN) for IP-10. Two investigators independently extracted data from eligible articles, and disagreements were resolved by discussing and reaching a consensus.

\section{Quality assessment}

According to the Cochrane Collaboration, two investigators independently reviewed the methodological quality of eligible articles by Quality Assessment of Diagnostic Accuracy Studies tool-2 (QUADAS-2) [31, 32]. Disagreements were resolved by consensus. Revman (version 5.3) was used to perform the quality assessment.

\section{Data analysis}

Excel was used to construct a two-by-two table, including TP, FP, FN, and TN for patients with PTB. Stata (version 14.0) was used to perform the data analysis. The index test had different optimal cut-offs. According to the recommendation of Cochrane Collaboration, the hierarchical summary receiver operating characteristic (HSROC) model by Rutter et al. was utilized when the index test was assessed by applying various thresholds [32, 33]. The HSROC curve was computed with the "metandi" command [34]. Prediction region presented possible point of sensitivity and specificity in the HSROC curve. The summary point showed the pooled sensitivity and specificity under the optimal threshold value. Confidence region reflected the possible summary point.

The main outcomes were the diagnostic performance of IP-10 for detecting PTB by the random effect model, as evaluated by the summary estimates of sensitivity, specificity, positive likelihood ratio (PLR), negative likelihood ratio (NLR), diagnostic odds ratio (DOR), and the area under the curve (AUC). Sensitivity, reflecting the ability of index test to detect patients, calculated by "Sensitivity $=\mathrm{TP} /(\mathrm{TP}+\mathrm{FN})$ ". Specificity, reflecting the ability of index test to eliminate disease-free, calculated by "Specificity = TN/(FP + TN $)$ ". PLR, a measure of index test for detection potential for disease, could be calculated by the formula "PLR = Sensitivity/(1-Specificity)". NLR, a measure of index test for detection potential for non-disease, could be calculated by the formula "NLR = (1-Sensitivity)/Specificity". DOR, a measure for overall accuracy of index test, could be calculated by the formula "DOR $=(\mathrm{TP} / \mathrm{FN}) /(\mathrm{FP} / \mathrm{TN})$ ". AUC, indicated how the index test was accurate, especially exceeded 0.90 . 95\% confidence interval (CI) was calculated by wilson method and no correction factor applied.

The $I^{2}$ value was not suitable for the quantification of heterogeneity in accuracy studies [35]. Thus, to explore potential sources of heterogeneity, we used a meta-regression analysis with the "midas" command. The intercept was zero. Seven subgroups were created: TB high-burden country (yes or no), study design type (cohort or not), age (adults or not), IP-10 method (multiplex cytokines assay or ELISA), IP-10 condition (unstimulated or stimulated), and HIV-infection status (yes/some or no).

The Deeks test was used to assess publication bias using the "midas" command [36]. No publication bias existed when studies evenly distributed on the sides of regression line or $P$ value exceeded 0.05 in Deeks' funnel plot.

The whole process of data analysis was described in Additional file 2. 


\section{Results}

Search results

In total, 1349 records were identified from our literature searches (Fig. 1). After removing 623 duplicates, we read titles and abstracts and excluded 682 records. An additional 447 records were non-eligible for various reasons (e.g., studies involving leprosy, Crohn's disease, pneumonia, monocyte chemotactic protein-1, interleukin-12, and interleukin-18), 73 records were animal experiments (mouse, calves, warthogs, etc.), 69 records were reviews, abstracts, and letters, 58 records focused on extra-PTB (pleural TB, TB meningitis, osteoarticular TB, etc.), and 5 records were nonEnglish (Chinese, Russian, Polish, etc.). Then, we reviewed the full texts of 44 articles. Ultimately, 18 articles were included in this study.

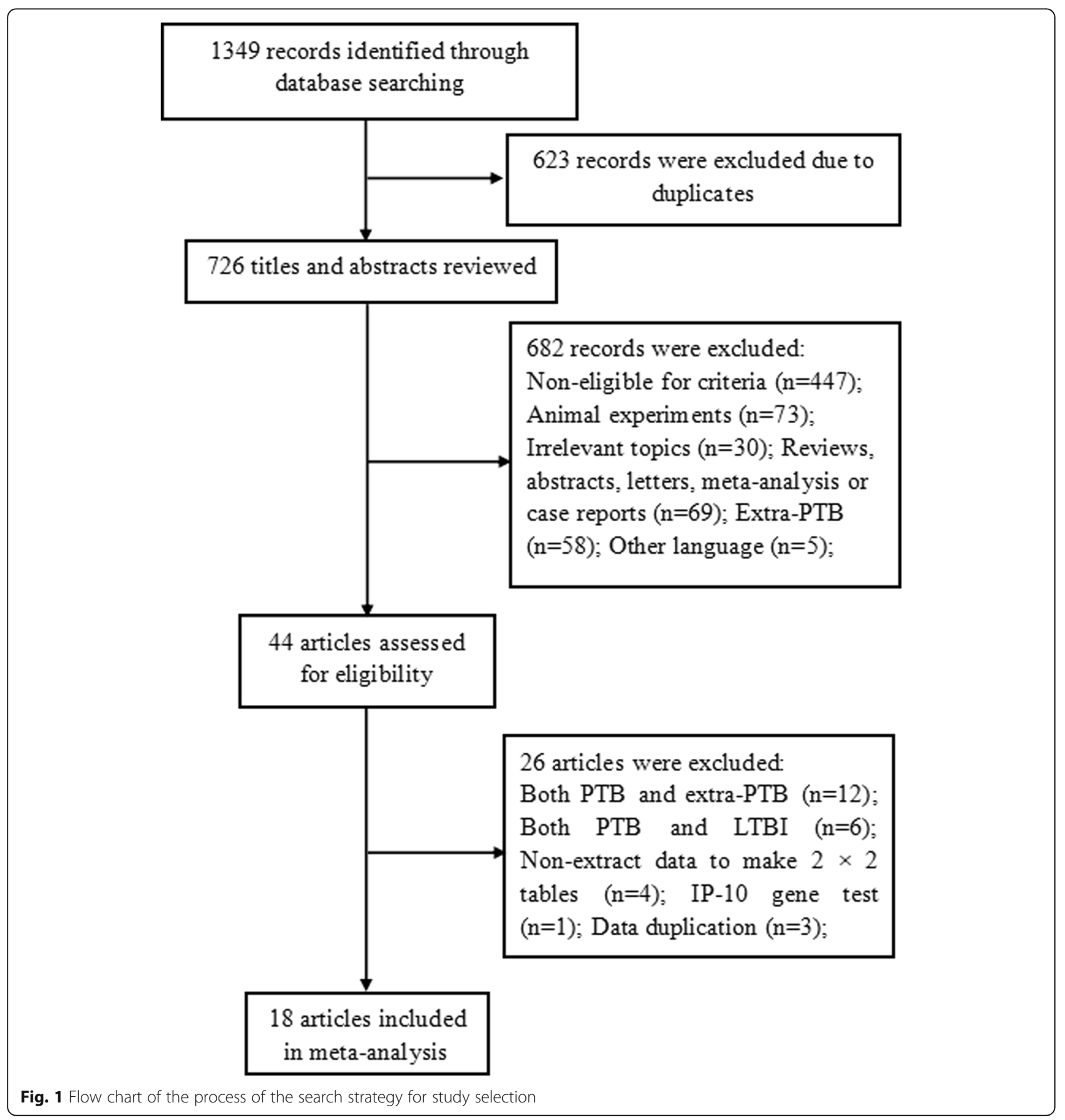




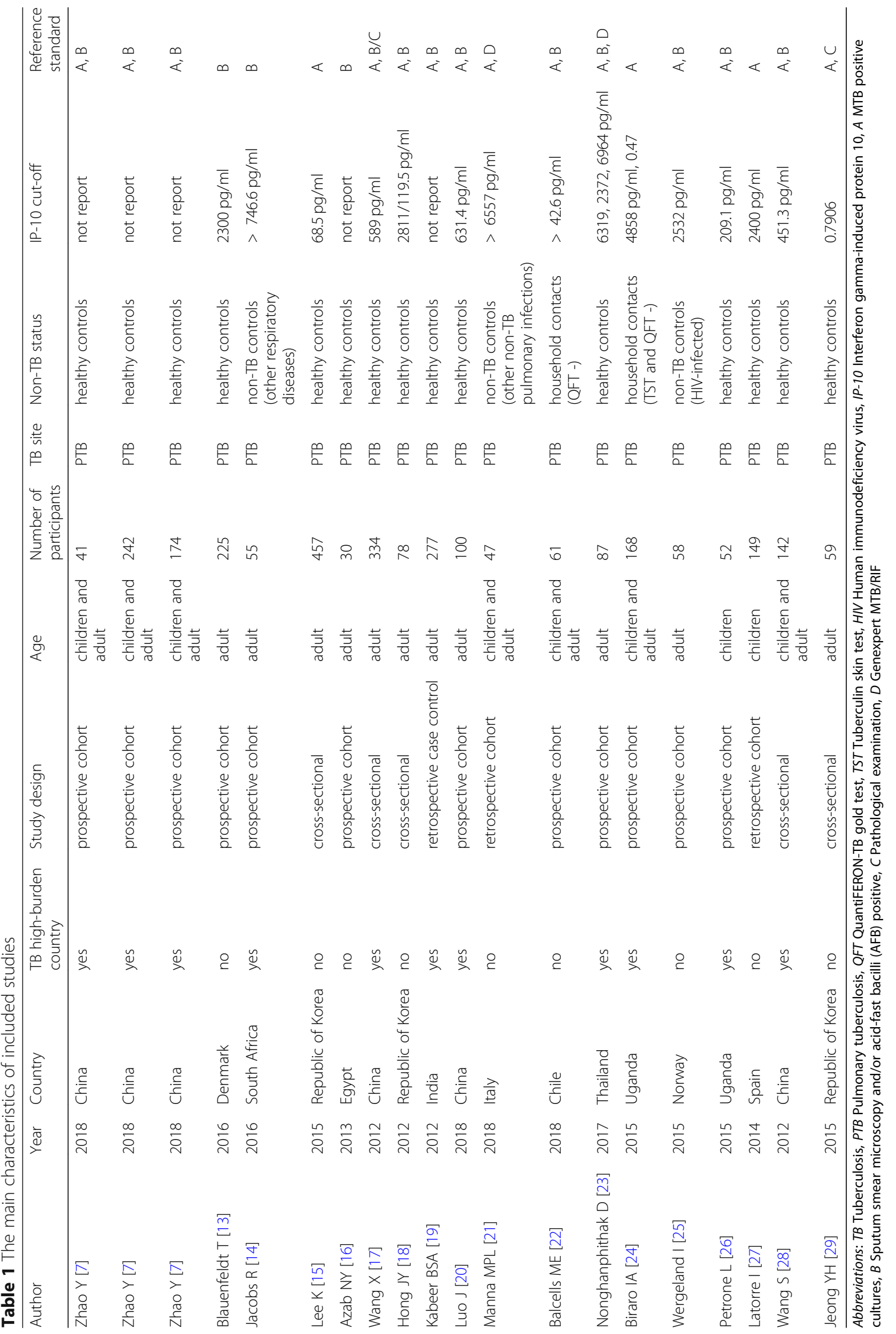




\section{Characteristics of included studies}

The main characteristics of the 18 articles, comprising 24 trials, are listed in Tables 1 and 2 [7, 13-29]. In total, 2836 participants were involved. The year of publication ranged from 2012 to 2018. Nine (50\%) studies were from TB high-burden countries (China, South Africa, India, Thailand, and Uganda), and nine (50\%) studies were from TB low-burden countries, according to WHO [2]. Study design, TB site, non-TB status, IP-10 cut-off, and reference standards are summarized in Table 1. IP-10 method, condition, HIV-infection status, cut-off values, sensitivity, specificity, TP, FP, FN, and TN of IP-10 for each trial are shown in Table 2.

\section{Quality of included studies}

The QUADAS-2 tool reflects the methodological quality of included articles (Additional file 3: Figure S1). Patient selection bias was unclear for five studies; one study used a case-control design [19] and four studies did not report the time and consecutiveness of patient enrolment $[17,21,23,27]$. Additionally, $50 \%$ of studies had unclear bias in index tests; in particular, we could not determine whether the results were interpreted in blind conditions [7, 18, 20, 23-25, 27-29]. One study had high risk of bias in the reference standard, which was clinical PTB by clinical presentation and radiological confirmation [16]. Flow and timing bias were unclear in three

Table 2 Baseline data of included studies

\begin{tabular}{|c|c|c|c|c|c|c|c|c|c|}
\hline Author & IP-10 method & IP-10 condition & $\begin{array}{l}\text { HIV- } \\
\text { infection }\end{array}$ & $\begin{array}{l}\text { Sensitivity } \\
(\%)\end{array}$ & $\begin{array}{l}\text { Specificity } \\
(\%)\end{array}$ & $\mathrm{TP}$ & $\mathrm{FP}$ & FN & $\overline{\mathrm{TN}}$ \\
\hline Zhao Y [7] & $\begin{array}{l}\text { multiplex cytokines } \\
\text { assay }\end{array}$ & unstimulated & no & 90.9 & 100 & 30 & 0 & 3 & 8 \\
\hline Zhao Y [7] & two cytokines assay & unstimulated & no & 90.14 & 86.21 & 192 & 4 & 21 & 25 \\
\hline Zhao Y [7] & two cytokines assay & unstimulated & no & 60.45 & 100 & 81 & 0 & 53 & 40 \\
\hline Blauenfeldt T [13] & ELISA & stimulated (TB Ag) & some & 82 & 97 & 53 & 5 & 12 & 155 \\
\hline Jacobs R [14] & $\begin{array}{l}\text { multiplex cytokines } \\
\text { assay }\end{array}$ & unstimulated & some & 86 & 73 & 19 & 9 & 3 & 24 \\
\hline Lee K [15] & ELISA & unstimulated & no & 70.1 & 88.3 & 141 & 30 & 60 & 226 \\
\hline Azab NY [16] & ELISA & stimulated (TB Ag) & no & 100 & 60 & 10 & 8 & 0 & 12 \\
\hline Wang X [17] & $\begin{array}{l}\text { multiplex cytokines } \\
\text { assay }\end{array}$ & stimulated (TB Ag) & no & 86 & 85.9 & 153 & 22 & 25 & 134 \\
\hline Hong JY [18] & ELISA & stimulated (TB Ag) & no & 97.8 & 87.5 & 45 & 4 & 1 & 28 \\
\hline Hong JY [18] & ELISA & unstimulated & no & 87.5 & 90.5 & 21 & 2 & 3 & 19 \\
\hline Kabeer BSA [19] & ELISA & stimulated (TB Ag) & no & 91.4 & 48 & 160 & 52 & 15 & 48 \\
\hline Luo J [20] & multiplex cytokine assay & unstimulated & no & 86 & 57.14 & 43 & 21 & 7 & 28 \\
\hline Manna MPL [21] & multiplex cytokine assay & stimulated (TB Ag-nil) & no & 80.77 & 85 & 21 & 3 & 5 & 17 \\
\hline Balcells ME [22] & multiplex cytokine assay & stimulated (TB Ag-nil) & no & 44.1 & 88.9 & 15 & 3 & 19 & 24 \\
\hline $\begin{array}{l}\text { Nonghanphithak D } \\
\text { [23] }\end{array}$ & ELISA & stimulated (TB Ag) & no & 79.2 & 87.2 & 38 & 5 & 10 & 34 \\
\hline $\begin{array}{l}\text { Nonghanphithak D } \\
\text { [23] }\end{array}$ & ELISA & unstimulated & no & 95.8 & 94.9 & 46 & 2 & 2 & 37 \\
\hline $\begin{array}{l}\text { Nonghanphithak D } \\
\text { [23] }\end{array}$ & ELISA & stimulated (TB Ag-nil) & no & 58.3 & 97.4 & 28 & 1 & 20 & 38 \\
\hline Biraro IA [24] & ELISA & stimulated (TB Ag) & some & 83.3 & 84.9 & 85 & 10 & 17 & 56 \\
\hline Biraro IA [24] & ELISA & $\begin{array}{l}\text { stimulated (TB Ag/mitogen } \\
\text { ratio) }\end{array}$ & some & 96.7 & 78.7 & 99 & 14 & 3 & 52 \\
\hline Wergeland I [25] & $\begin{array}{l}\text { multiplex cytokines } \\
\text { assay }\end{array}$ & unstimulated & yes & 100 & 92.3 & 6 & 4 & 0 & 48 \\
\hline Petrone L [26] & ELISA & unstimulated & no & 79 & 93.9 & 15 & 2 & 4 & 31 \\
\hline Latorre I [27] & ELISA & stimulated (TB Ag) & no & 66.7 & 76.7 & 8 & 32 & 4 & 105 \\
\hline Wang S [28] & ELISA & stimulated (TB Ag) & no & 89.4 & 81.6 & 59 & 14 & 7 & 62 \\
\hline Jeong YH [29] & $\begin{array}{l}\text { multiplex cytokines } \\
\text { assay }\end{array}$ & $\begin{array}{l}\text { stimulated (TB Ag/mitogen } \\
\text { ratio) }\end{array}$ & no & 93.9 & 100 & 31 & 0 & 2 & 26 \\
\hline
\end{tabular}


studies, in which patients were lost in the analysis [19-21]. The applicability concerns were generally low.

\section{Summary statistics}

A total of 2836 participants, comprising 3219 blood samples were included. The sensitivity for IP-10 was 0.86 (95\% CI: $0.80-0.90$ ) and the specificity was 0.88 (95\% CI: 0.82-0.92). The pooled PLR was 7.00 (95\% CI: 4.76-10.30), and the pooled NLR was 0.16 (95\% CI: 0.12-0.23). The pooled DOR was 43.01 (95\% CI: $25.80-$ 71.69), indicating that the discriminatory effect of IP-10 was good. The AUC was 0.93 (95\% CI: 0.91-0.95), showed the accuracy of IP-10 was good. Figure 2 shows the HSROC curves for IP-10, under the optimal threshold value, the pooled sensitivity and specificity were 0.86 and 0.88 , respectively.

\section{Heterogeneity}

As shown in Table 3, heterogeneity was assessed by a meta-regression analysis. Heterogeneity was not detected with respect to TB high-burden versus TB low-burden countries $(P=0.83)$, cohort versus other study design types $(P=0.55)$, adults versus children (with or without adults) $(P=0.59)$, multiplex cytokine assay versus ELISA to detect IP-10 $(P=0.73)$, IP-10 stimulation or not $(P=$ $0.72)$, and HIV infection or not $(P=0.53)$.

\section{Publication bias}

Deeks' funnel plot showed no statistical significance $(P=0.20)$, indicating no striking publication bias in this study (Additional file 4: Figure S2).

\section{Discussion}

PTB is still a major cause of death worldwide, especially in immunocompromised individuals and children younger than 5 years $[37,38]$. The accurate detection and timely treatment of PTB are important components of the "End TB Strategy" globally [39]. Currently, methods for detecting PTB depend on the region, BCGvaccinated status, HIV status, etc. The search for new markers for the auxiliary diagnosis of PTB is ongoing.

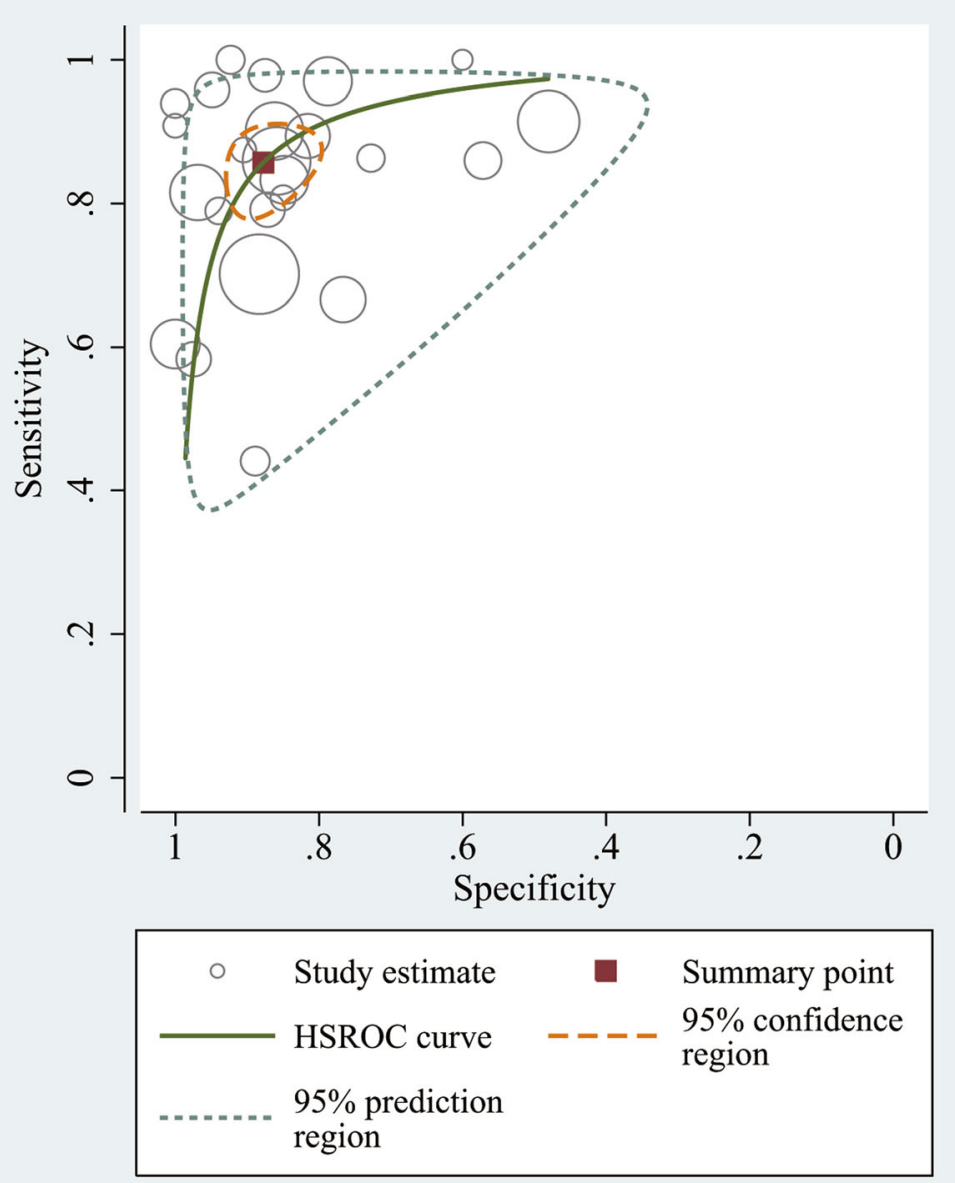

Fig. 2 The HSROC curve for assessment of IP-10 for PTB 
Table 3 Heterogeneity assessment

\begin{tabular}{|c|c|c|c|c|}
\hline Covariate & Studies & $\begin{array}{l}\text { Sensitivity } \\
(95 \%)\end{array}$ & $\begin{array}{l}\text { Specificity } \\
(95 \%)\end{array}$ & $\begin{array}{l}P \text { Value } \\
\text { (Bivariate } \\
\text { Model) }\end{array}$ \\
\hline \multicolumn{5}{|c|}{ TB high-burden country } \\
\hline Yes & 14 & $0.86(0.81-0.92)$ & $0.86(0.80-0.93)$ & 0.83 \\
\hline No & 10 & $0.85(0.76-0.93)$ & $0.89(0.83-0.96)$ & \\
\hline \multicolumn{5}{|c|}{ Design type } \\
\hline Cohort & 17 & $0.84(0.78-0.90)$ & $0.89(0.83-0.94)$ & 0.55 \\
\hline $\begin{array}{l}\text { Cross-sectional/ } \\
\text { case-control }\end{array}$ & 7 & $0.89(0.82-0.96)$ & $0.85(0.75-0.95)$ & \\
\hline \multicolumn{5}{|c|}{ Age } \\
\hline Adults & 14 & $0.88(0.82-0.94)$ & $0.87(0.80-0.93)$ & 0.59 \\
\hline $\begin{array}{l}\text { Children and } \\
\text { adults/children }\end{array}$ & 10 & $0.83(0.74-0.91)$ & $0.89(0.82-0.96)$ & \\
\hline \multicolumn{5}{|c|}{ IP-10 method } \\
\hline $\begin{array}{l}\text { Multiplex } \\
\text { cytokines assay }\end{array}$ & 10 & $0.84(0.75-0.92)$ & $0.89(0.82-0.96)$ & 0.73 \\
\hline ELISA & 14 & $0.87(0.81-0.93)$ & $0.87(0.80-0.93)$ & \\
\hline \multicolumn{5}{|c|}{ IP-10 condition } \\
\hline Stimulated & 14 & $0.86(0.80-0.92)$ & $0.86(0.79-0.93)$ & 0.72 \\
\hline Unstimulated & 10 & $0.86(0.78-0.93)$ & $0.90(0.83-0.96)$ & \\
\hline \multicolumn{5}{|c|}{ HIV-infected } \\
\hline Yes/some & 5 & $0.90(0.82-0.98)$ & $0.88(0.79-0.98)$ & 0.53 \\
\hline No & 19 & $0.84(0.79-0.90)$ & $0.87(0.82-0.93)$ & \\
\hline
\end{tabular}

Several studies have shown that IP-10 is a promising marker for PTB detection [7, 13-29].

In 2014, Guo et al. published a meta-analysis of studies of IP-10 for diagnosing TB [40]. The diagnostic performance of IP-10 was moderate. In this study, both PTB and extra-PTB individuals were included, and plasma and pleural effusion samples were included. However, the diagnostic standards for PTB and extra-PTB were different. Pleural effusion detection is more traumatic than the use of peripheral venous blood.

Considering these limitations, we performed a metaanalysis to evaluate the overall diagnostic performance of blood IP-10 as a potential biomarker for detecting PTB. We found that IP-10 could be a valuable detection tool (sensitivity: $86 \%$, specificity: $88 \%$ ). The PLR $(7.00>1.00)$ suggested that IP-10 had good detection potential for PTB. The NLR $(0.16<1.00)$ indicated that IP-10 distinguished non-TB individuals well. The DOR (43.01) indicated a good overall performance of IP-10 in discriminating between PTB and non-TB.
The TST and IGRA, as immunodiagnostic tests, are recommended for the auxiliary diagnosis of PTB by the WHO [2]. The TST could show cross-reactivity in BCGvaccinated individuals. However, IP-10 is less influenced by BCG vaccination [7]. Ruhwald et al. reported that IP10 has a much higher sensitivity $(92.5 \%)$ when compared to the TST (73.9\%), and suggested that IP-10 is an alternative biomarker of TST [41]. The recently developed IGRA can overcome some limitations of TST. However, it lacks power when applied to children and individuals coinfected with HIV $[9,14]$. IP-10 could be produced at a high level in these populations $[42,43]$. Vanini et al. showed that the sensitivity is $66.7 \%$ for IP-10-based test and $52.4 \%$ for the IGRA in HIV-infected individuals [44].

In bivariate analyses, TB-burden country, study design, age, IP-10 detection method, assay conditions, and HIV infection status were not significant sources of heterogeneity. We also found that the diagnostic performance of IP-10 was similar in multiplex cytokine assays and ELISA (sensitivity: $84 \%$ vs. $87 \%$, specificity: $89 \%$ vs. $87 \%$ ). These two methods were comparable with respect to reliability and reproducibility [20]. Considering the cost, ELISA is preferred over multiplex cytokine assays. Stimulated and unstimulated IP-10 had similar diagnostic accuracies for PTB, suggesting that IP-10 could be detected in both conditions. IP-10 had a higher diagnostic potential in HIV-infected individuals, consistent with previous findings [45].

Certainly, our meta-analysis had several limitations. First, we enrolled studies which had various cut-offs of IP-10 assays. In most situations, the investigators of included studies might choose the different cut-offs according to their aims. Second, IP-10 assays are usually performed in combination with conventional tests, but we did not address the reliability and incremental benefit of adding IP-10 to other tests. Third, some studies included patients with PTB after treatment while others did not. Furthermore, the severity and extent of PTB might vary. These factors might influence the diagnostic potential of IP-10. Fourth, heterogeneity could not be ignored. Although the TBburden country, design type, age, IP-10 method, IP-10 condition and HIV-infection status were not significant sources of heterogeneity in this meta-regression analysis $(P>0.05)$, they could also increase the heterogeneity and reduce the generalizability of the overall performance of IP-10. Furthermore, intercurrent diseases (diabetes mellitus and malignancy) in the included studies might influence heterogeneity.

Despite the low probability of publication bias, it was a concern. Based on the linguistic abilities of our team, only studies written in English were included. The true potential of IP-10 for discriminating PTB from non-TB might be lower than we reported. 


\section{Conclusions}

In conclusion, this meta-analysis shows that IP-10 is a promising and reliable marker for differentiating PTB from non-TB. Updated global TB reports should consider IP-10 as an auxiliary diagnostic method for PTB. Furthermore, large, multi-center, prospective studies are warranted to support our findings.

\section{Abbreviations \\ Cl: Confidence interval; DOR: Diagnostic odds ratio; FN: False negative; FP: False positive; HSROC: Hierarchical summary receiver operating characteristic; IP-10: Interferon gamma-induced protein 10; NLR: Negative likelihood ratio; PLR: Positive likelihood ratio; PTB: Pulmonary tuberculosis; QUADAS-2: Quality assessment of diagnostic accuracy studies tool-2; \\ TN: True negative; TP: True positive}

\section{Authors' contributions}

DM had full access to all data in the study and takes responsibility for the integrity of data and accuracy of its analysis. $X Q, T X, X S, Y Q, L G, Y Y, Y Z, W L$, and $\mathrm{PH}$ contributed substantially to the study design, data analysis and interpretation, and writing of the manuscript. All authors read and approved the final manuscript.

\section{Funding}

This work was supported by the National Science Foundation of China $(81330016,81630038,81771634,81842011)$, the National Key R\&D Program of China (2017YFA 0104200), the grants from the Ministry of Education of China (IRT0935), the grants from the Science and Technology Bureau of Sichuan Province (2016TD0002), and the grant from the clinical discipline program (Neonatology) from the Ministry of Health of China (1311200003303).

\section{Availability of data and materials}

The data generated in this study are included in published article and its supplementary information files.

\section{Ethics approval and consent to participate}

Not applicable.

\section{Consent for publication}

Not applicable.

\section{Competing interests}

The authors declare that they have no competing interests.

\begin{abstract}
Author details
'Department of Pediatrics, West China Second University Hospital, Sichuan University, Chengdu 610041, Sichuan, China. ${ }^{2}$ Key Laboratory of Obstetric \& Gynecologic and Pediatric Diseases and Birth Defects of Ministry of Education, Sichuan University, Chengdu, China. ${ }^{3}$ Evidence Based Social Science Research Center, School of Public Health, Lanzhou University, Lanzhou, China.
\end{abstract}

Received: 29 June 2019 Accepted: 12 September 2019

Published online: 30 October 2019

\section{Supplementary information}

Supplementary information accompanies this paper at https://doi.org/10. 1186/s12879-019-4466-5.

Additional file 1: Table S1. Pubmed, Web of science, Embase and Cochrane library strategies.

Additional file 2. The whole process of data analysis.

Additional file 3: Figure S1. Methodological quality of the included articles.

Additional file 4: Figure S2. Deeks' funnel plot the included articles.

\section{Author details}

Supplementary information accompanies this paper at https://doi.org/10. 1186/s12879-019-4466-5. 'Department of Pediatrics, West China Second University Hospital, Sichuan University, Chengdu 610041, Sichuan, China. ${ }^{2}$ Key Laboratory of Obstetric \& Gynecologic and Pediatric Diseases and Birth Defects of Ministry of Education, Sichuan University, Chengdu, China. ${ }^{3}$ Evidence Based Social Science Research Center, School of Public Health, Lanzhou University, Lanzhou, China.

Received: 29 June 2019 Accepted: 12 September 2019

Published online: 30 October 2019

\section{References}

1. Lawn SD, Zumla Al. Tuberculosis. Lancet. 2011;378(9785):57-72.

2. The World Health Organizations. Global tuberculosis report 2018. Available at: www.aidsdatahub.org/global-tuberculosis-report-2018-who-2018.

3. Denkinger CM, Schumacher SG, Boehme CC, Dendukuri N, Pai M, Steingart KR. Xpert MTB/RIF assay for the diagnosis of extrapulmonary tuberculosis: a systematic review and meta-analysis. Eur Respir J. 2014;44(2):435-46.

4. Ford N, Matteelli A, Shubber Z, Hermans S, Meintjes G, Grinsztejn B, et al. TB as a cause of hospitalization and in-hospital mortality among people living with HIV worldwide: a systematic review and meta-analysis. J Int AIDS Soc. 2016;19(1):20714.

5. O'Garra A, Redford PS, McNab FW, Bloom Cl, Wilkinson RJ, Berry MP. The immune response in tuberculosis. Annu Rev Immunol. 2013;31:475-527.

6. Wallis RS, Pai M, Menzies D, Doherty TM, Walzl G, Perkins MD, et al. Biomarkers and diagnostics for tuberculosis: progress, needs, and translation into practice. Lancet. 2010;375(9729):1920-37.

7. Zhao $Y$, Yang $X$, Zhang $X, Y u$ Q, Zhao P, Wang J, et al. IP-10 and RANTES as biomarkers for pulmonary tuberculosis diagnosis and monitoring. Tuberculosis. 2018;111:45-53.

8. Connell TG, Tebruegge M, Ritz N, Bryant P, Curtis N. The potential danger of a solely interferon-gamma release assay-based approach to testing for latent mycobacterium tuberculosis infection in children. Thorax. 2011;66(3):263-4.

9. Haustein T, Ridout DA, Hartley JC, Thaker U, Shingadia D, Klein NJ, et al. The likelihood of an indeterminate test result from a whole-blood interferongamma release assay for the diagnosis of mycobacterium tuberculosis infection in children correlates with age and immune status. Pediatr Infect Dis J. 2009:28(8):669-73.

10. Azzurri A, Sow OY, Amedei A, Bah B, Diallo S, Peri G, et al. IFN-gammainducible protein 10 and pentraxin 3 plasma levels are tools for monitoring inflammation and disease activity in mycobacterium tuberculosis infection. Microbes Infect. 2005;7(1):1-8.

11. Qiu X, Tang Y, Yue Y, Zeng Y, Li W, Qu Y, et al. Accuracy of interferon- $Y$ induced protein 10 for diagnosing latent tuberculosis infection: a systematic review and meta-analysis. Clin Microbiol Infect. 2019;25(6):667-72.

12. Aabye MG, Latorre I, Diaz J, Maldonado J, Mialdea I, Eugen-Olsen J, et al. Dried plasma spots in the diagnosis of tuberculosis: IP-10 release assay on filter paper. Eur Respir J. 2013;42(2):495-503.

13. Blauenfeldt $\mathrm{T}$, Wagner $\mathrm{D}$, Aabye $\mathrm{M}$, Heyckendorf J, Lange $\mathrm{B}$, Lange $\mathrm{C}$, et al. Thermostability of IFN-gamma and IP-10 release assays for latent infection with mycobacterium tuberculosis: a TBnet study. Tuberculosis. 2016:98:7-12.

14. Jacobs R, Malherbe S, Loxton AG, Stanley K, van der Spuy G, Walzl G, et al. Identification of novel host biomarkers in plasma as candidates for the immunodiagnosis of tuberculosis disease and monitoring of tuberculosis treatment response. Oncotarget. 2016;7(36):57581-92.

15. Lee K, Chung W, Jung Y, Kim Y, Park J, Sheen S, et al. CXCR3 ligands as clinical markers for pulmonary tuberculosis. Int J Tuberc Lung Dis. 2015;19(2):191-9.

16. Azab NY, Elmahallawy I, Sharara G, Abdel-Atti E. The utility of the interferon gamma-inducible protein-10 (IP-10) level in bronchoalveolar lavage and blood in the diagnosis of tuberculosis. Egypt J Chest Dis Tuberc. 2013;62:629-34.

17. Wang X, Jiang J, Cao Z, Yang B, Zhang J, Cheng X. Diagnostic performance of multiplex cytokine and chemokine assay for tuberculosis. Tuberculosis. 2012;92(6):513-20

18. Hong JY, Jung GS, Kim H, Kim YM, Lee HJ, Cho S-N, et al. Efficacy of inducible protein 10 as a biomarker for the diagnosis of tuberculosis. Int J Infect Dis. 2012:16(12):E855-E9.

19. Syed Ahamed Kabeer B, Raman B, Thomas A, Perumal V, Raja A. Role of QuantiFERON-TB gold, interferon gamma inducible protein-10 and tuberculin skin test in active tuberculosis diagnosis. PLoS One. 2010;5(2):e9051. 
20. Luo J, Zhang M, Yan B, Li F, Guan S, Chang K, et al. Diagnostic performance of plasma cytokine biosignature combination and MCP-1 as individual biomarkers for differentiating stages of mycobacterium tuberculosis infection. J Infect. 2018;78(4):281-91.

21. La Manna MP, Orlando V, Li Donni P, Sireci G, Di Carlo P, Cascio A, et al. Identification of plasma biomarkers for discrimination between tuberculosis infection/disease and pulmonary non tuberculosis disease. PLoS One. 2018; 13(3):e0192664.

22. Balcells ME, Ruiz-Tagle C, Tiznado C, Garcia P, Naves R. Diagnostic performance of GM-CSF and IL-2 in response to long-term specific-antigen cell stimulation in patients with active and latent tuberculosis infection. Tuberculosis. 2018;112:110-9.

23. Nonghanphithak D, Reechaipichitkul W, Namwat W, Naranbhai V, Faksri K Chemokines additional to IFN-gamma can be used to differentiate among mycobacterium tuberculosis infection possibilities and provide evidence of an early clearance phenotype. Tuberculosis. 2017;105:28-34.

24. Biraro IA, Kimuda S, Egesa M, Cose S, Webb EL, Joloba M, et al. The use of interferon gamma inducible protein 10 as a potential biomarker in the diagnosis of latent tuberculosis infection in Uganda. PLoS One. 2016;11(1):e0146098.

25. Wergeland I, Pullar N, Assmus J, Ueland T, Tonby K, Feruglio S, et al. IP-10 differentiates between active and latent tuberculosis irrespective of HIV status and declines during therapy. J Infect. 2015;70(4):381-91.

26. Petrone L, Cannas A, Aloi F, Nsubuga M, Sserumkuma J, Nazziwa RA, et al. Blood or urine IP-10 cannot discriminate between active tuberculosis and respiratory diseases different from tuberculosis in children. Biomed Res Int. 2015;2015:589471.

27. Latorre I, Diaz J, Mialdea I, Serra-Vidal M, Altet N, Prat C, et al. IP-10 is an accurate biomarker for the diagnosis of tuberculosis in children. J Inf Secur. 2014;69(6):590-9.

28. Wang S, Diao N, Lu C, Wu J, Gao Y, Chen J, et al. Evaluation of the diagnostic potential of IP-10 and IL-2 as biomarkers for the diagnosis of active and latent tuberculosis in a BCG-vaccinated population. PLoS One. 2012;7(12):e51338.

29. Jeong $Y H$, Hur Y-G, Lee H, Kim S, Cho J-E, Chang J, et al. Discrimination between active and latent tuberculosis based on ratio of antigen-specific to mitogen-induced IP-10 production. J Clin Microbiol. 2015;53(2):504-10

30. Mclnnes MDF, Moher D, Thombs BD, McGrath TA, Bossuyt PM, Clifford T, et al. Preferred reporting items for a systematic review and meta-analysis of diagnostic test accuracy studies: the PRISMA-DTA statement. JAMA. 2018;319(4):388-96.

31. Whiting PF, Rutjes AW, Westwood ME, Mallett S, Deeks JJ, Reitsma JB, et al. QUADAS-2: a revised tool for the quality assessment of diagnostic accuracy studies. Ann Intern Med. 2011;155(8):529-36

32. Macaskill P, Gatsonis C, Deeks J, Harbord R, Takwoingi Y. Analysing and presenting results. In: Deeks JJ, Bossuyt PM, Gatsonis C, editors. Cochrane handbook for systematic reviews of diagnostic test accuracy; 2010.

33. Rutter CM, Gatsonis CA. A hierarchical regression approach to meta-analysis of diagnostic test accuracy evaluations. Stat Med. 2001;20(19):2865-84.

34. Harbord RM, Whiting P. Metandi: meta-analysis of diagnostic accuracy using hierarchical logistic regression. Stata J. 2009;9:211-29.

35. Higgins JPT, Thompson SG. Quantifying heterogeneity in a meta-analysis. Stat Med. 2002;21(11):1539-58.

36. Deeks JJ, Macaskill P, Irwig L. The performance of tests of publication bias and other sample size effects in systematic reviews of diagnostic test accuracy was assessed. J Clin Epidemiol. 2005;58(9):882-93.

37. Jenkins HE, Yuen CM, Rodriguez CA, Nathavitharana RR, McLaughlin MM, Donald $P$, et al. Mortality in children diagnosed with tuberculosis: a systematic review and meta-analysis. Lancet Infect Dis. 2017;17(3):285-95.

38. Holm LL, Rose MV, Kimaro G, Bygbjerg IC, Mfinanga SG, Ravn P, et al. A comparison of interferon-gamma and IP-10 for the diagnosis of tuberculosis. Pediatrics. 2014;134(6):e1568-75.

39. Uplekar M, Weil D, Lonnroth K, Jaramillo E, Lienhardt C, Dias HM, et al. WHO's new end TB strategy. Lancet. 2015;385(9979):1799-801.

40. Guo SJ, Jia LQ, Hu QJ, Long HY, Pang CS, Wen FQ. Diagnostic accuracy of interferon gamma-induced protein 10 for tuberculosis: a meta-analysis. Int J Clin Exp Med. 2014;7(1):93-100

41. Ruhwald M, Bodmer T, Maier C, Jepsen M, Haaland MB, Eugen-Olsen J, et al. Evaluating the potential of IP-10 and MCP-2 as biomarkers for the diagnosis of tuberculosis. Eur Respir J. 2008;32(6):1607-15.

42. Ruhwald M, Aabye MG, Ravn P. IP-10 release assays in the diagnosis of tuberculosis infection: current status and future directions. Expert Rev Mol Diagn. 2012;12(2):175-87.

43. Mandalakas AM, Kirchner HL, Walzl G, Gie RP, Schaaf HS, Cotton MF, et al. Optimizing the detection of recent tuberculosis infection in children in a high tuberculosis-HIV burden setting. Am J Respir Crit Care Med. 2015;191(7):820-30.
44. Vanini V, Petruccioli E, Gioia C, Cuzzi G, Orchi N, Rianda A, et al. IP-10 is an additional marker for tuberculosis (TB) detection in HIV-infected persons in a low-TB endemic country. J Infect. 2012;65(1):49-59.

45. Aabye MG, Ruhwald M, PrayGod G, Jeremiah K, Faurholt-Jepsen M, FaurholtJepsen $\mathrm{D}$, et al. Potential of interferon-gamma-inducible protein 10 in improving tuberculosis diagnosis in HIV-infected patients. Eur Respir J. 2010;36:1488-90.

\section{Publisher's Note}

Springer Nature remains neutral with regard to jurisdictional claims in published maps and institutional affiliations.
Ready to submit your research? Choose BMC and benefit from:

- fast, convenient online submission

- thorough peer review by experienced researchers in your field

- rapid publication on acceptance

- support for research data, including large and complex data types

- gold Open Access which fosters wider collaboration and increased citations

- maximum visibility for your research: over $100 \mathrm{M}$ website views per year

At $\mathrm{BMC}$, research is always in progress.

Learn more biomedcentral.com/submissions 